
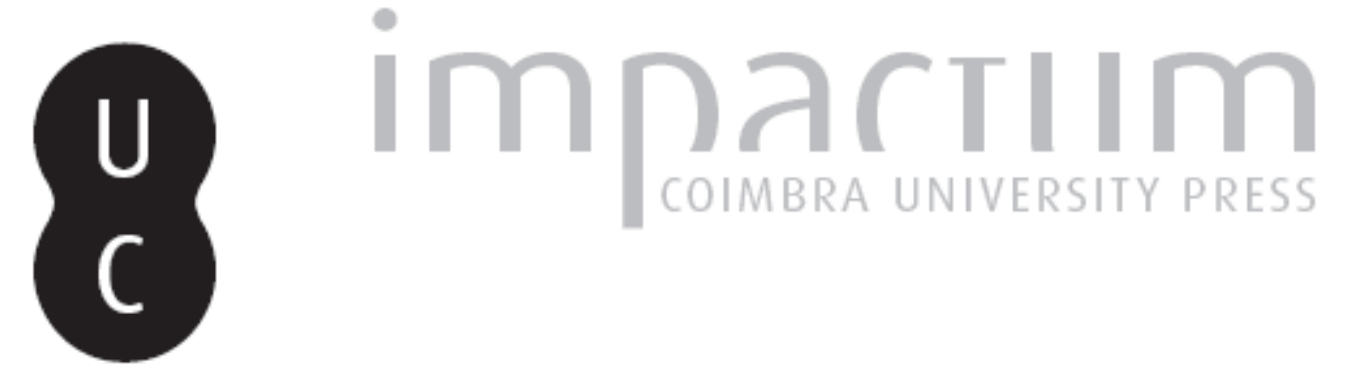

\title{
Uma Universidade que se renova
}

Autor(es): $\quad$ Fonseca, Fernando Taveira da

Publicado por: Imprensa da Universidade de Coimbra

URL persistente:

URl:http://hdl.handle.net/10316.2/42749

DOI:

DOI:https://doi.org/10.14195/1647-8436_46_47_2

Accessed : $\quad$ 26-Apr-2023 13:39:24

A navegação consulta e descarregamento dos títulos inseridos nas Bibliotecas Digitais UC Digitalis, UC Pombalina e UC Impactum, pressupõem a aceitação plena e sem reservas dos Termos e Condições de Uso destas Bibliotecas Digitais, disponíveis em https://digitalis.uc.pt/pt-pt/termos.

Conforme exposto nos referidos Termos e Condições de Uso, o descarregamento de títulos de acesso restrito requer uma licença válida de autorização devendo o utilizador aceder ao(s) documento(s) a partir de um endereço de IP da instituição detentora da supramencionada licença.

Ao utilizador é apenas permitido o descarregamento para uso pessoal, pelo que o emprego do(s) título(s) descarregado(s) para outro fim, designadamente comercial, carece de autorização do respetivo autor ou editor da obra.

Na medida em que todas as obras da UC Digitalis se encontram protegidas pelo Código do Direito de Autor e Direitos Conexos e demais legislação aplicável, toda a cópia, parcial ou total, deste documento, nos casos em que é legalmente admitida, deverá conter ou fazer-se acompanhar por este aviso.

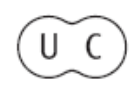




\section{BOLETIM DA \\ BIBLIOTECA GERAL DA UNIVERSIDADE DE COIMBRA}

VOL. 46/47 (2015/2016)

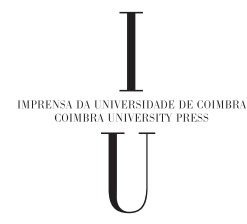




\title{
Uma Universidade que se renova
}

\author{
Fernando Taveira da Fonseca ${ }^{1}$
}

\section{RESUMO}

O percurso biográfico de D. Francisco de Lemos está intimamente ligado à Universidade num dos seus momentos cruciais. Tendo feito toda a sua formação académica em Coimbra, antes de 1772, ele irá desempenhar um papel principal na preparação e na implantação da reforma universitária que nesse ano se formaliza através dos novos Estatutos. A reforma assenta numa base institucional e económica que, em grande parte, permanece; mas opera uma revolução nos conteúdos e nos métodos de ensino. Tentaremos aqui, em síntese, traçar um quadro que englobe estas duas realidades que mutuamente se iluminam.

\section{PALAVRAS-CHAVE}

Francisco de Lemos (1735-1822); Universidade de Coimbra, quadro institucional, reforma.

\section{ABSTRACT}

The life story of D. Francisco de Lemos is intertwined with a crucial moment in the history of the University of Coimbra. Having completed there his academic education before 1772 , he would play a major role in the preparation and the implementation of the university reform whose inception was the granting of the new statutes, in September of that year. The reform was based on previous institutional and economic grounds which underwent almost no change; but it operated a revolution in the curricula and the teaching methods. We will try here to draw a summary picture which encompasses these two realities that illuminate each other.

1 Faculdade de Letras da Universidade de Coimbra - Centro de História da Sociedade e da Cultura da FLUC - fertaveira@gmail.com 


\section{KEYWORDS}

Francisco de Lemos (1735-1822); University of Coimbra, institutional framework, reform.

O percurso biográfico de Francisco de Lemos Faria Pereira Coutinho está intimamente ligado à universidade de Coimbra: nela ingressou ainda adolescente (matriculou-se em Instituta, o primeiro ano dos estudos de Direito, a 23 de Janeiro de 1748, meses antes de completar treze anos de idade); concluiu o seu percurso estudantil passados seis anos, tomando o grau de doutor em Cânones (24 de Outubro de 1754), pouco depois de perfazer os dezanove, já como freire professo da Ordem de S. Bento de Avis e colegial - depois de ter sido porcionista - do Colégio dos Militares, do qual foi reitor de 1762 a 1766; candidato ao professorado universitário, entrou em concurso para a cadeira de Sexto das Decretais (6 de Março de 1765), tentativa infrutífera, uma vez que já se preparava, esvaziando a universidade dos seus quadros docentes, a reforma de 1772 . Foi, contudo, a partir de 1770 que mais intimamente cruzou o seu destino com o da alma mater conimbricense: nomeado reitor em Maio desse ano, trabalhou directamente nos planos da reforma, juntamente com o seu irmão e mentor João Pereira Ramos de Azeredo Coutinho, na qualidade de membro da Junta de Providência Literária (que elaborou os novos Estatutos depois de ter redigido o Compêndio Histórico -1771, um texto crítico da realidade universitária anterior mas já também programático) e protagonizou, no terreno, a "nova fundação", agora na qualidade de reformador-reitor, em estreito diálogo com o poder central, organizando, construindo, e finalmente fazendo a apologia (com a sua Relação Geral do Estado da Universidade, em 1777) da obra que ajudara a criar, num momento em que a desgraça política do principal artífice, o Marquês de Pombal, ameaçava também a sua feitura. Voltará em 1799 ao reitorado, depois de o ter deixado em 
1779 para assumir exclusivamente as funções de bispo-conde de Coimbra, exercendo o novo mandato até pouco antes do seu falecimento, ocorrido em 16 de Abril de $1822^{2}$.

É desta universidade que se pretende traçar um perfil que atenda às linhas essenciais que a definem: situando-nos no momento em que se opera formalmente uma viragem substancial - o dia 29 de Setembro de 1772, no qual foram solenemente apresentados pelo Marquês de Pombal a todo o corpo universitário os novos Estatutos - olharemos para o antes e o depois, no intuito de perscrutar as suas características estruturais, as continuidades e as mudanças.

\section{"... pera bom governo, e conservação da Republica Christam"}

Se em todas as comunidades "bem ordenadas" se deve procurar o serviço de Deus, "nesta Universidade ha pera isto mayor obrigação" uma vez que nela se ensina não apenas "sua santa doctrina" como igualmente "as mais sciencias necessarias pera bom governo, e conservação da republica Christam" ${ }^{\prime 3}$. Esta afirmação com que abrem os Estatutos que mais longamente vigoraram na universidade de Coimbra (os de 1597, denominados Estatutos Velhos) denota a clara consciência da dimensão social e política da universidade. Já em 1559, D. Sebastião se decidira a continuar a obra começada por seu avô, D. João III, de dar novos estatutos à escola conimbricense "por ser de tanto serviço de Nosso Senhor e bem dos meus reynos e senhorios"'t.

2 Os dados biográficos aqui apresentados foram colhidos em:

TEIXEIRA, António José - Apontamentos para a biografia de D. Francisco de Lemos de Faria Pereira Coutinho. O Instituto. 2a série, vol. 37 (1889-1890), p. 1-16;

RODRIGUES, Manuel Augusto - Biblioteca e bens de D. Francisco de Lemos e da Mitra de Coimbra. Coimbra : Arquivo da Universidade de Coimbra, 1984. Introdução, p. V-XII.

3 Estatutos da Universidade de Coimbra (1654). Coimbra : por ordem da Universidade, 1987. liv. I, tít. I, p. 1.

4 Estatutos da Universidade de Coimbra (1559). Coimbra : Universidade de Coimbra, 1965. p. 10. 
De forma bem mais explícita, passados dois séculos, D. Francisco de Lemos assinala que "não se deve olhar para a Universidade como um corpo isolado e concentrado em si mesmo, como ordinariamente se faz; mas sim como um corpo formado no seio do Estado para, por meio dos sábios que cria, difundir a Luz da Sabedoria por todas as partes da Monarchia; para vivificar e animar todos os Ramos da Administração Publica; e para promover a felicidade dos homens" ${ }^{\prime \prime}$. Na mesma linha de pensamento - e seguramente com inspiração do mesmo autor - os Estatutos de 1772 vincam que os "Supremos Poderes, Espiritual e Temporal" concederam às universidades a prerrogativa de conferir graus com o "único fim" de "se governarem, e regerem por eles, no provimento das Dignidades, Benefícios, Ministérios, e Empregos, que pela sua maior gravidade e importância só se costumam conferir aos que com elles se acham Graduados, na supposição de serem estes os mais sábios, e idóneos para bem servirem à Igreja e ao Estado"6. Fica assim claramente expressa a natureza instrumental da universidade, embora não menos a eminência das suas funções (preparar para o alto serviço da Igreja e do Estado) e o poder de que goza ao formular um juízo decisivo das capacidades dos que aspiram as esse alto serviço.

Daqui derivam as suas características essenciais: o elenco dos saberes que ministra; a sua organização orientada para esse múnus fundamental de ensinar e qualificar, implicando quer o exercício de um poder interno organizador, quer a exigência de financiamento; 0 seu relacionamento com os outros poderes, principalmente o poder régio. E ao exercer a sua função, constitui-se como lugar central de muitos percursos biográficos, pólo de uma procura social que se mede pela intensidade de uma corrente que simultaneamente a demanda e que dela flui, mensurável pelas matrículas e pelas graduações.

5 LEMOS, Francisco de - Relação Geral do Estado da Universidade (1777). Coimbra : Por Ordem da Universidade, 1980. p. 232.

6 Estatutos da Universidade de Coimbra (1772). liv. I, tit. IV, cap. VI, p. 192. 


\section{Uma estrutura poliédrica}

Ao situarmo-nos no ponto de viragem que atrás referimos, a reforma de 1772, lançaremos primeiramente um olhar retrospectivo (com particular atenção ao século XVIII) para, em seguida, nos darmos conta das principais mudanças operadas.

A estrutura da universidade organiza-se à volta da sua função central - ensinar, avaliar e graduar, envolvendo "lentes" e "ouvintes" - e inclui funções subsidiárias que poderemos resumidamente sintetizar com as designações de fazenda, justiça e serviços: o todo é enquadrado pelo exercício da autoridade na sua dupla vertente interna e externa. Exploremos brevemente cada um destes aspectos.

O elenco dos saberes ministrados - aquilo que a expressão coeva designava de 'ciências' - é o comum a muitas outras universidades da Época Moderna: Teologia, Direito Canónico, Direito Civil e Medicina. Se atentarmos nos níveis de frequência das respectivas faculdades, é clara a predominância jurídica (à volta de $87 \%$ entre 1577 e 1772) com primazia para o Direito Canónico (72\%), aumentada em cada momento de novo surto positivo de matrículas (a partir de 1670 e no meio da década de 1720). Cânones era um curso ambivalente para o serviço eclesiástico e para o serviço régio - e, de acordo com um testemunho, em 1752, da Mesa da Consciência e ordens à qual competia, a nível do governo central, a gestão dos assuntos universitários - decididamente mais acessível que o de Direito Civil. Medicina era uma opção menos cotada, a última das ciências, muitas vezes designada, até nos seus textos fundamentais, não como ciência mas como arte (uma pequena obra que acompanhava todo o percurso dos estudantes médicos era precisamente a Ars Medicinalis - ou Tekne latrikê - de Galeno). A Teologia, com ser um estudo preferencial dos regulares que forneciam também a quase totalidade do corpo de professores, tinha uma amplitude que ultrapassava o contingente de matriculados nesta faculdade (5,6\% do total entre 1577 e 1772). 
Ensinava-se também em muitos dos colégios pertencentes às ordens religiosas e militares (e que chegaram a ser cerca de duas dezenas) até níveis que incluíam a formatura: os estudantes incorporavam-se depois na universidade, que validava os estudos assim realizados, para obter os graus de licenciado e de doutor ou mestre.

Situação peculiar era a dos estudos literários e da Filosofia, conduzindo igualmente às graduações de bacharel, licenciado e mestre, aos quais superintendiam, desde 1555, os Jesuítas. Fundado o Colégio das Artes, em 1548, sob a batuta de Mestre André de Gouveia, com larga autonomia e um elenco prestigiado de professores, na sua maioria humanistas reputados e experientes que aquele mestre trouxera consigo de Bordéus, a morte prematura do Principal e as suspeitas de heresia lançadas contra alguns dos professores levaram D. João III a confiar a direcção do Colégio e a organização dos estudos à recém-fundada Companhia de Jesus. Permaneceu, contudo, a Faculdade de Artes como parte intrínseca da universidade: o registo dos actos e da colação dos graus, assim como dos vexames (favores ou louvores atribuídos aos bacharéis em Artes como complemento da sua avaliação final) era efectuado, como o das faculdades maiores, pelo Secretário da universidade, nos mesmos livros de registo.

Ensinar e avaliar era o múnus dos professores, proprietários das cadeiras, rigorosamente escalonadas pela respectiva dignidade e pelo nível de remuneração que cabia a cada uma delas. A grande divisão fazia-se entre cadeiras grandes e pequenas (cátedras e catedrilhas), mas, no seu conjunto, constituíam degraus sucessivos que cada lente deveria percorrer até chegar ao topo, a cadeira de Prima, designação comum a todas as faculdades que derivava da hora matutina a que era leccionada, logo seguida em dignidade pela de Véspera, ocupando o centro da tarde. As outras cadeiras grandes tomavam já a designação das matérias nelas leccionadas: Escoto e Escritura Grande, em Teologia; Decreto, Sexto [das Decretais] e Clementinas, 
em Cânones; Digesto Velho e Três Livros do Código, em Leis; Avicena e Anatomia em Medicina. Das catedrilhas, que repetiam, passando-as rapidamente, matérias das cadeiras grandes, importa, contudo, salientar as de Instituta (com base nas Instituições de Justiniano) que constituíam o curso preparatório, no primeiro ano, de todos os matriculados em Direito (Canónico ou Civil).

O corpo docente, no que concerne aos proprietários, não era, assim, muito amplo (rondaria as três dezenas). Mas completava-se pelos condutários, professores sem propriedade de cadeira que já eram, contudo, "filhos da folha" (entenda-se, folha de ordenados) recebendo um estipêndio anual módico e que uma provisão de 1730 declara como substitutos preferenciais, nas ausências dos lentes proprietários; e pelos opositores, os doutorados que orbitavam a universidade e entravam em concurso quando eram declaradas vacaturas, quase sempre enquadrados institucionalmente (exceptuava-se Medicina), seja nas casas religiosas, seja nos colégios, chamados seculares, de S. Pedro e de S. Paulo. Integrando colegiais e porcionistas (estes últimos oriundos das mais gradas famílias de nobres titulares), os colégios seculares eram comunidades sujeitas também a uma regra e autogovernadas, de acesso extremamente selectivo, trampolim não apenas para a carreira docente universitária - os colegiais vieram a constituir o grosso do professorado nas faculdades jurídicas - mas igualmente para as dignidades eclesiásticas e os cargos da governação.

O acesso ao corpo docente, sobretudo nos momentos iniciais da implantação em Coimbra protagonizados por D. João III, dependeu grandemente do convite do monarca que escolheu nomes consagrados para as cadeiras de maior responsabilidade; regulamentaram-se logo a seguir, contudo, os procedimentos concursais, desde a declaração de vacatura, a cargo do Reitor, às provas públicas a prestar - lições de ponto (na base de um tema escolhido com vinte e quatro horas de antecedência) e ostentações (espécie de improviso sobre um tema comum escolhido no próprio dia, e em três dias 
sucessivos) - os quais foram sobretudo aplicados para preencher lugares de início de carreira. Na verdade, quando vagavam cadeiras do topo, o procedimento mais comum era o ascenso, a deslocação um degrau acima de todos os que se encontravam nas cadeiras inferiores: preenchido o último lugar da escala com um condutário, se o houvesse, só quando tal não era possível se abria nova vaga.

Até 1654 foi reconhecido aos estudantes o direito de votar nos concursos para provimento das cadeiras, com votos diferenciados consoante o seu adiantamento nos estudos (exarados em quadradinhos de papel que os escrutinadores iam enfiando numa agulha, fazendo-os 'entrar em linha de conta'). Uma provisão régia de 25 de Abril desse ano retirou-Ihes essa prerrogativa. Simultaneamente, deslocava-se o centro de decisão: os votos dos estudantes foram substituídos por pareceres ou votos consultivos individuais do Reitor, Cancelário e lentes de Prima e Véspera das faculdades; ficava vedado, por isso, o procedimento anterior de dar posse imediata (sujeita embora a confirmação régia) ao candidato mais votado. Aumentava assim decisivamente a interferência do poder régio num dos pontos mais sensíveis da vida universitária como era a constituição do seu corpo docente.

Dos pareceres enviados pelos vogais que chegaram até nós colige-se o perfil ideal do professor: a capacidade científica, expressa no poder de memorização capaz de mobilizar para a eficácia argumentativa um vasto leque de conhecimentos e de autoridades, a facilidade de expressão e comunicação, a aplicação ao estudo, os dotes naturais de inteligência e clareza.

Precedida, por vezes, de uma longa espera (no período que vai de 1700 a 1771, o intervalo entre a obtenção do grau de doutor e a propriedade de uma cátedra foi, em média, de 27 anos para os Teólogos, 14 a 15 anos para os juristas e 4 para os médicos), a actividade docente, segundo as faculdades, tinha duração variável e desfechos distintos: mais longa para os lentes de Medicina (26 anos, em média), 
muito mais curta para os de Teologia (cerca de 14 anos), os quais, regra geral, se confinavam à carreira universitária; de 12 a 17 anos para os lentes juristas, neste caso por força da sua passagem para outros cargos, desde a Relação do Porto aos tribunais superiores da Corte, o que, sendo encarado como normal, fazia da sua passagem pela docência uma etapa intermédia e da Universidade uma reserva de qualidade. Esta possibilidade de promoção era um dos elementos importantes do sistema de compensações dos professores, que incluía, para todos, os ordenados, as propinas recebidas nos actos e graus (importante parcela que, nas faculdades jurídicas, em muitos casos excedia largamente o valor daqueles); e, para alguns, o acesso a benefícios eclesiásticos de apresentação da Universidade (canonicatos magistrais e doutorais na maioria das dioceses do Reino), a possibilidade de obtenção de tenças para familiares chegados e as prestações em cereais (trigo e cevada). Além disso, porém (e, porventura, mais que tudo), a dignidade, simbolizada pelas precedências nas manifestações cerimoniais e que a jubilação (em princípio, depois de vinte anos de actividade docente em cadeira grande), quando ocorria, redobrava.

No outro pólo da relação pedagógica estavam os estudantes. O seu contingente, conhecido desde que há registo regular de matrículas (1577) foi sucessivamente aumentando, como que por patamares (número médio anual de matriculados de 1016 entre 1577-1669; de 1639, entre 1670-1717; e de 2766, entre 1718-1770) mas com oscilações importantes nas quais se reflectem diversas conjunturas: um tempo de "revolução educativa" que percorre toda a Europa e aqui se assinala também, nas décadas finais do século XVI e iniciais do século XVII, bem visível no acelerar das matrículas em Coimbra (que só a grande peste da passagem do século interrompe) e, concomitantemente, na numerosa nação portuguesa de Salamanca; um tempo de dificuldades, no qual à crise do século XVII (o ponto de viragem 
andaria por 1620), que afecta quase toda a Europa universitária, se juntam a diminuição da actividade económica, o aperto fiscal do último período da monarquia dual e os constrangimentos da guerra, depois de 1640. A paz de 1668 permite o ressurgir imediato da matrícula que sofre nova inflexão com a outra guerra (a da sucessão de Espanha), para subir a valores nunca antes atingidos a partir do final da segunda década de setecentos. Neste aumento teve influência notável a corrente de "brasileiros" - filhos de colonos e de colonizadores - engrossada pelas disponibilidades que a mineração do ouro começava a proporcionar.

É que a atracção de Coimbra - ou, se quisermos, a procura social de qualificações universitárias, sobretudo nos domínios do Direito, como já vimos - é generalizada. A cartografia da origem dos graduados cobre todo o território do continente, em estreita correlação com a densidade populacional, abrange as ilhas da Madeira e dos Açores, mas sobretudo o Brasil onde aos pólos primitivos - Baía, Pernambuco e Rio de Janeiro, por força dos colégios jesuítas aí implantados - se junta, nas primeiras décadas de setecentos, a região de Minas Gerais.

Em termos sociais, encontramos idêntica abrangência: desde os filhos dos "grandes" que formam o contingente dos porcionistas de $\mathrm{S}$. Pedro e S. Paulo, como vimos, até aos "pobres" (que prestam serviços a outros estudantes, professores ou comunidades da cidade) e aos filhos de oficiais mecânicos; de permeio um conjunto de categorias que apontam para estratos médio-altos do espectro social: nobres locais, letrados, homens de negócio, lavradores, militares (perfazendo cerca de $78 \%$ de uma amostra representativa de pais de bacharéis juristas).

Os cursos são longos: oito anos de oito meses (as matrículas de Outubro e de Maio delimitavam o ciclo lectivo) para os estudantes juristas - seis anos até obter o grau de bacharel e mais dois para alcançar a formatura, a porta de saída para a vida prática. Para teólogos e médicos mais longo ainda, se tivermos em conta que 
uns e outros teriam que fazer o curso de Artes, podendo, no quarto ano, o chamado ano de intrância, frequentar a faculdade da sua escolha da parte da manhã, continuando, pela tarde, o estudo da Filosofia.

Se bem que nem todos permaneçam na cidade depois de se matricularem (há momentos, depois da instauração das matrículas incertas, em 1660, em que se pode falar de frequência itinerante), constituem um grupo específico que o traje identifica e o nível cultural põe em destaque, jovem e desenraizado do meio familiar, criando uma cultura própria com rituais de iniciação e solidariedades regionais, de que encontramos ecos abundantes nos textos jocosos do Palito Métrico ou nos relatos de esporádicos episódios de violência que opõem os estudantes entre si e, por vezes, à população da cidade. Não obstante, misturam-se com ela - vivem em casas e quartos arrendados - usufruem dos serviços de amas, lavadeiras e moços de recados, frequentam o barbeiro, as estalagens ou as lojas dos conserveiros; e é entre a população da cidade que os estudantes médicos encontram os fiadores que apresentam para poderem receber os seus partidos, bolsas de estudo reservadas aos que de entre eles pudessem atestar a sua condição de cristãos-velhos.

O seu ritmo de vida é pautado pelas lições, de segunda a sábado, com o descanso semanal da quinta-feira (o assueto, excepto se na semana houvesse festa de guarda) e do domingo, seguindo o ciclo da luz (a lição de Prima era às sete e meia até à Páscoa e daí por diante às seis e meia); os dias de préstito (a que todos os membros da universidade tinham de acorrer sub poena praestiti iuramenti, daí o seu nome) eram também dias sem lições embora neles pudesse haver actos e colação de graus. De véspera de Natal à Epifania e de Ramos à Pascoela era tempo de férias como o eram os meses de Agosto e Setembro. Os estudantes viviam em Coimbra o tempo da mocidade (a maioria dos juristas cursava, entre os 18 e os 25 anos de idade, médicos e teólogos seriam um pouco mais velhos). Se "a matrícula 
fazia do homem um estudante" ${ }^{\prime \prime}$, o estudo dava-Ihe a possibilidade de exercer os cargos de letras, alcandorando-o, por vezes aos mais elevados lugares do governo da República.

Como dissemos acima, à volta desta função central que define a universidade, organizam-se outras funções e serviços. Desde logo, a que tem a ver com o privilégio do foro académico que eximia os membros da comunidade universitária dos tribunais ordinários, nas causas cíveis e crimes, postulando assim que a instituição dispusesse de órgãos judiciais próprios, a que presidia o Conservador mas em estreita articulação com o Reitor. O recurso deste tribunal ia directamente para a Casa da Suplicação, o que diz da sua importância. Oficiais subalternos (escrivães, solicitadores, contador e distribuidor, advogados), uma pequena força policial (o meirinho e dez homens da vara) e o carcereiro completavam o aparelho judicial punitivo universitário.

Mais complexo era o mecanismo que geria a fazenda. O financiamento da Escola tinha por base a gestão largamente autónoma de um conjunto de rendas, constituídas basicamente por dízimos e direitos senhoriais (foros e rações), generosamente atribuídas por D. João III com conivência do poder eclesiástico, e cuja cobrança era feita pelo sistema de contrato: os rendeiros comprometiam-se a um pagamento anual fixo e em datas pré-estabelecidas a troco de recolherem para si os rendimentos devidos à Universidade; o prebendeiro, cumulativamente, arrematava a massa global e, para além disso, exercia funções de tesoureiro, por exemplo, pagando os ordenados a professores e oficiais.

7 OLIVEIRA, António de - O quotidiano da Academia. In História da Universidade em Portugal. Coimbra : Universidade de Coimbra ; Lisboa : Fundação Calouste Gulbenkian, 1997. vol. I, tomo II, p. 619-692. Um estudo fundamental para a compreensão deste tema. 
O ritmo dos contratos era quadrienal, mas a falência dos dois últimos prebendeiros (1716 e 1720) levou a que se eliminasse este elo intermédio. Esta resolução que fez subir, de imediato, os montantes arrecadados, implicou uma mais directa intervenção do corpo administrativo: a Mesa da Fazenda, constituída por quatro professores de cadeiras grandes, um por cada faculdade (emanação do Conselho de Deputados, que incluía outros cinco elementos não lentes, mas pelo menos bacharéis), pela qual passam os mais variados assuntos da administração económica ordinária; os escrivães (da fazenda, da receita e da despesa, dos contos), os agentes e sacadores e também os mordomos, olheiros da Universidade, espalhados por diversos pontos do país, zelando pelos interesses dela; e, sobretudo, o síndico, oficial que encarnava a personalidade jurídica da instituição no que respeitava à fazenda, privilégios e jurisdição, consultando e informando, requerendo, chamando a atenção para irregularidades, protagonizando, em grande parte, a complexa operação da arrematação das rendas. O contencioso, neste domínio, estava a cargo do ouvidor, uma vez que a fazenda universitária era equiparada à fazenda real, podendo proceder contra os seus devedores por via executiva.

Uma boa parte dos serviços destinava-se também ao apoio material: carniceiros e picadeiros, assim como recoveiros com quem se celebravam contratos para o fornecimento de carne e peixe respectivamente (tabelando preços, estabelecendo a regularidade do abastecimento e condições de preferência) ou o transporte de bens e valores, com percursos, prazos e custos definidos; ou às funções cultuais e cerimoniais (capelães, moços da capela, cirieiro, músicos); às necessárias operações de vigilância e manutenção (contínuos, guardas da universidade, da livraria e do cartório, relojoeiro, carpinteiro, pedreiro).

Mas importa não esquecer o apoio directo à actividade docente: os bedéis vigiam a assiduidade dos lentes (as faltas destes são-lhes descontadas no ordenado), são arautos e andadores que anunciam 
exames e actos académicos e levam a casa dos lentes as conclusões que hão-se ser debatidas, registam o tempo cursado pelos estudantes, entregam aos lentes as propinas que eles pagam; e o secretário que regista, em livros próprios, matrículas, provas de curso, actos e graus, passa certidões de frequência e cartas de curso.

O governo da Universidade é eminentemente colegial: ao ConseIho de Conselheiros - do qual estão excluídos os professores - cabe tratar "as cousas que tocão às cadeiras e lições e bom regimento dellas" (Estatutos, 1559), mormente a substituição dos lentes quando se prevê uma ausência mais prolongada, e a penalização das faltas não justificadas nos "conselhos de multas"; já o Conselho de Deputados superintende nos assuntos de administração económica (na prática era substituído nas suas competências pela Mesa da Fazenda, a que já aludimos); juntos, conselheiros e deputados, formavam o Claustro, que elegia oficiais para os senhorios da Universidade, debatia os assuntos graves para Roma ou os que se houvessem de tratar com o monarca; o Claustro Pleno, no qual residia todo o poder e autoridade da Universidade, era constituído pelo conjunto dos professores, pelos conselheiros e deputados, pelo chanceler, conservador e síndico e tratava dos negócios mais relevantes (gastos grandes e obras custosas, modificação dos Estatutos, conflitos com a cidade, recebimentos reais, entre outros).

Preside aos conselhos o Reitor que convoca, propõe os assuntos a tratar, tem voto de qualidade e é interlocutor privilegiado com o Protector, o monarca: escolhido por este a partir de uma lista tríplice enviada pela Universidade (a partir de 1722 desaparece esta prática) ocupa uma posição intermédia como longa manus do poder central e como cabeça de toda a Universidade, a quem compete também uma intervenção directa nos exames e concursos (manda calar argumentantes e opositores quando lhe parece), guarda os relógios de areia que medem o tempo, vigia a prática pedagógica dos professores e 
o comportamento dos estudantes, assina os editos de vacatura das cadeiras e é sede última do poder jurisdicional da Universidade.

\section{A nova fundação}

Como já vimos, o momento simbólico no qual se realizou a Reforma da Universidade de Coimbra, ocorreu a 29 de Setembro de 1772: na tarde desse dia, o Marquês de Pombal, Visitador e Lugar-Tenente do rei, apresentou a todo o corpo da Universidade "o novo Estatuto, escrito em letra de mam" ${ }^{\prime \prime}$. Os reformadores haviam apontado, como causa primeira do atraso de que acusavam a Escola, o texto estatutário pelo qual ela se regia até então - na substância, o promulgado em 1597 - os chamados Estatutos Velhos, como pode facilmente comprovar-se pela leitura do Compêndio Histórico do Estado da Universidade de Coimbra, elaborado, em 1771, pela Junta de Providência Literária. Toda a diatribe aí vazada contra os Jesuítas não é mais do que o desenvolvimento de um silogismo: os Jesuítas haviam sido os autores dos anteriores Estatutos; sendo eles moralmente desqualificados (todo o apêndice à terceira parte do Compêndio é uma longa demonstração desta premissa) a norma por eles criada era substancialmente dolosa e, por isso, devia ser revogada. Pombal não hesita mesmo em afirmar, na correspondência que manteve com D. Francisco de Lemos, que os juramentos feitos pelos monarcas anteriores, na sua qualidade de protectores da Universidade, pelo qual se obrigavam a guardar os estatutos, privilégios, liberdades, usos e costumes da Escola Ihes haviam sido "extorquidos com sacrílego atrevimento e egual ignorância" . Ao texto normativo agora promulgado era, por isso, atribuída uma

8 VASCONCELOS, António de - Escritos Vários Relativos à Universidade Dionisiana. Reedição preparada por Manuel Augusto Rodrigues. Coimbra : Arquivo da Universidade de Coimbra, 1987. p. 348.

9 BRAGA, Teófilo Braga - Historia da Universidade de Coimbra. Lisboa : Academia Real das Ciências, 1892-1902. Tomo 3 (1898), p. 441. 
natureza essencialmente regeneradora, nele se consubstanciando a essência da "nova fundação".

Não oferece dúvida, porém, que a Reforma da Universidade de Coimbra tem de ser encarada como um processo ainda longo que teve os seus inícios, décadas antes, em tentativas frustradas, em debates científicos, em medidas administrativas que o foram preparando. Lembremos apenas a vontade de reforma da faculdade de Medicina, bem expressa na intenção de $D$. João $V$ de convidar o célebre professor da universidade de Leiden (entre 1710 e 1735 aproximadamente), Hermann Boerhaave, para o magistério coimbrão ou nas opiniões formuladas pelos diversos membros do júri acerca dos opositores que entraram em concurso para a cadeira de Anatomia, em 1739, abrindo um debate acerca da modernização do ensino da Medicina que renasce na década de cinquenta; o contributo - nem sempre isento de polémica - trazido pelos escritos de Ribeiro Sanches, de Jacob de Castro Sarmento, de Luís António de Verney, entre outros; o estrangulamento - a que já nos referimos - de que foi objecto o corpo dos professores, visível a partir da década de cinquenta do século XVIII, quando diversos concursos (1751, para Teologia, 1759 para Leis, 1765 para Cânones) não tiveram, com uma única excepção, qualquer consequência a nível de recrutamento ou de promoção de docentes e os que estavam no activo viram a sua carreira paralisada. Sem esquecermos que, mesmo entre aqueles que mais duramente eram criticados pelo seu imobilismo, se encontram sinais anunciadores de adesão às novas concepções científicas. Na verdade, para Décio Ruivo Martins, o edital do Reitor do Colégio das Artes de 1746, tantas vezes invocado como emblema da posição retrógrada dos Jesuítas, deverá ser antes interpretado de outra maneira: a proibição de aderir às doutrinas de Descartes, Gassendo ou Newton "formalizada em termos tão vigorosos permite supor [...] que a sua redacção e inclusão naquele documento só se justificava porque, na realidade, os temas da Filosofia Moderna, e particularmente da Filosofia newtoniana, já 
constituíam objecto de análise nas aulas daquele Colégio, embora não oficialmente". E corrobora a sua asserção mencionando o Elenchus Quaestionum, redigido em 1754 e extensivo a todos os colégios da Companhia da província portuguesa: um dos seus aspectos mais significativos traduzia-se "na perspectiva moderna proposta para o ensino das matérias relacionadas com a Física"10.

A Reforma trouxe, como grande novidade, a criação das duas novas faculdades de Matemática (a Matemática era antes estudada como cadeira isolada) e Filosofia, assim introduzindo no elenco dos estudos superiores as ciências exactas e as ciências da natureza: conjuntamente com a Medicina, agora também remodelada nos seus fundamentos, passaram a constituir as chamadas Faculdades Naturais. Tanto como - ou talvez mais do que - esta inclusão de novos conteúdos é o carácter propedêutico de que estes saberes se irão revestir também para as faculdades de Direito e de Teologia. Aos estudantes que pretendessem ingressar nestas últimas era exigido que estudassem "privativamente o Primeiro Anno do Curso Mathematico", no qual eram leccionados os Elementos de Geometria (que "são a Lógica, praticada com a maior perfeição que he possível ao entendimento humano") "como subsidio importante ao aproveitamento que devem ter nas respectivas faculdades"11; para os que pretendessem seguir Direito, era-Ihes necessária também a frequência da cadeira de História Natural. Saberes propedêuticos e, como tais, dimensionadores da forma mentis que se queria implantar na universidade recriada.

A par dos conteúdos, uma profunda revolução no método e no que respeita às funções dos professores. Quanto ao método, os termos com que explicitamente ele é definido condensam-se na expressão sintético-compendiário-demonstrativo. Assim se opunha ao prati-

10 MARTINS, Décio Ruivo - As ciências físico-matemáticas em Portugal e a Reforma Pombalina. In O Marquês de Pombal e a Universidade. Coimbra : Imprensa da Universidade, 2000. p. 198-199.

11 Estatutos da Universidade (1772). liv. III, parte II, tít. II, cap. I. 
cado anteriormente, que era textual, analítico, cíclico e cumulativo. Pretendia-se agora introduzir a progressão gradativa do mais simples ao mais complexo (nas matérias e nas cadeiras, rigorosamente escalonadas ao longo dos anos do curso, sucessivamente, em introdutórias, sintéticas e analíticas); substituir os antigos textos - repositórios de temas, problemas, soluções e autoridades (tais como as compilações legislativas, as sumas, os escritos galénicos, os comentários) - por compêndios nos quais se expusessem os fundamentos de uma ciência que progressivamente se iam desvendando e desenvolvendo; abolir a forma tradicional de leccionação - a lectio e o ditado, dando origem à apostila - acerca de temas soltos colhidos nos textos, durante um ciclo de quatro anos, por um sistema contínuo e constantemente exploratório dos conhecimentos adquiridos pelos estudantes (revisões da matéria no final de cada aula, exercícios semanais e mensais, exames anuais), de onde derivava um particular cuidado em verificar a sua assiduidade: cada estudante ocupava um lugar fixo, numerado (ainda hoje podemos ver esta disposição em alguns anfiteatros então construídos) para que o professor, que deveria conhecer a cada aluno nominalmente, verificasse de imediato e anotasse as ausências; o Reitor poderia vigiar o andamento das aulas desde as tribunas que abriam sobre os gerais, ligadas por um corredor propositadamente aberto para esse efeito. Novidade que aparece pela primeira vez na história da universidade era a possibilidade de retenção no mesmo ano se o nível de aprendizagem não fosse satisfatório. Na avaliação, as disputas, o método por excelência do período anterior, foram substituídas por interrogatórios conduzidos pelo método socrático.

Os cursos foram reduzidos na sua duração (adoptou-se o modelo de cinco anos para a obtenção da qualificação necessária ao exercício da ciência professada e de mais um ano para a obtenção dos graus de licenciado e doutor), mas os requisitos de acesso aos estudos universitários tornaram-se muito mais exigentes (a nível da idade mínima, da preparação científica e da idoneidade moral), numa linha 
de 'malthusianismo ilustrado' visando limitar o que se pensava ser o excessivo número de estudantes. A estes foi exigido ainda um contributo substancial para obviar aos custos da sua formação. O sistema anterior protelava para a realização dos exames e para a tomada dos graus o pagamento de propinas (no momento da matrícula, o emolumento era mínimo, dez réis) que iam directamente para os professores e oficiais intervenientes; agora deslocava-se a despesa: não se pagavam propinas nos actos, mas a matrícula implicava o pagamento de 12.800 réis, em cada ano e em duas prestações anuais (o substancial aumento de ordenados dos lentes promulgado pelo Marquês derivou, em grande parte da incorporação das anteriores propinas). Se compararmos as despesas de um e outro destes sistemas é evidente o enorme aumento de encargos que então se verificou.

Foi instaurada uma nova dinâmica nas congregações dos professores, antes apenas dedicadas a aspectos administrativos: eram agora em cada uma das Faculdades (havendo também uma congregação conjunta das três Faculdades Naturais), algo que se assemelhava a academias internas às quais continuava a competir a organização formal das tarefas docentes e de avaliação, mas principalmente a superintendência em tudo o que dizia respeito ao domínio científico; aos docentes, libertos da administração económica, uma vez que a Mesa da Fazenda foi substituída por uma Junta da Fazenda composta por colegiais de S. Pedro, S. Paulo e do Colégio dos Militares, é incumbida também a responsabilidade de serem "inventores" e de irem incorporando nas suas lições os avanços da ciência, próprios ou alheios, e de organizarem para a disciplina de que fossem responsáveis o respectivo compêndio. Não deixa de haver, por isso, uma certa contradição entre a rigorosa, pormenorizada e impositiva regulamentação dos curricula, da ordem e conteúdo das cadeiras e esta, também obrigatória, abertura à novidade.

O carácter demonstrativo do novo método e o perfil definido para os professores tiveram uma dupla consequência prática. Pri- 
meiro, na reformulação do corpo docente: para além dos lentes os titulares e os substitutos permanentes, na sua grande maioria recrutados por nomeação depois de afastados quase todos os que haviam servido antes da Reforma - vamos encontrar preparadores e demonstradores, os primeiros executando tarefas laboratoriais ou de manipulação e elaboração de peças museológicas, os segundos prestando um auxílio directo nas aulas pela ilustração prática das prelecções dos lentes, muitas vezes como primeiro patamar da carreira docente. Mas, fundamentalmente, as componentes de observação e de experimentação, postulavam a existência de estabelecimentos específicos onde elas pudessem ser eficazmente postas em prática. Assim é que, para os estudos médicos, se determinou a construção do Hospital, do Teatro Anatómico e do Dispensatório Farmacêutico; para a Faculdade de Matemática, a do Observatório Astronómico; para a de Filosofia, a dos Gabinetes de História Natural e de Física Experimental, do Laboratório Químico e do Jardim Botânico.

Era, com efeito, uma nova Universidade que nascia, sobre um alicerce administrativo que se manteve em grande parte inalterado mas com uma ampliação logística notável (de que convém não esquecer a incorporação, em 1774, das rendas que haviam sido dos Jesuítas) e uma reforma científica e pedagógica que se aproxima de uma revolução. Se a formulação normativa era indispensável como suporte, a implantação prática exigia uma convicção sólida e um esforço continuado e pertinaz. Protagonista maior em todo este processo, como referíamos ao princípio, foi D. Francisco de Lemos cuja memória nunca será demais enaltecer. 